\title{
The Research of Oil Pipeline Patrol by UAV in the First Sub-Factory of PCOC
}

\author{
Fanping Meng ${ }^{a}{ }^{*}$, Min Li ${ }^{b}$, Juanjuan Wang ${ }^{c}$, Li Zhang ${ }^{d}$, Tingxiang Zhong ${ }^{\mathrm{e}}$, \\ Qingping Cong ${ }^{f}$ and Yuexin $\mathrm{An}^{\mathrm{g}}$ \\ Digital and Information Management of PCOC., Xian, Shaanxi 710021, China \\ amfp_cq@petrochina.com.cn, blimin3_cq@petrochina.com.cn, ${ }^{c} w j j 3$ _cq@petrochina.com.cn, \\ dz1220_cq@petrochina.com.cn, èzhongtx_cq@petrochina.com.cn, ${ }^{\mathrm{f}} \mathrm{cqp}$ 1_cq@petrochina.com.cn, \\ gayx_cq@petrochina.com.cn \\ *The Corresponding author
}

Keywords: Oil pipeline patrol; Labor patrol; UAV patrol

\begin{abstract}
The main body of PCOC (Petrochina Changqing Oilfield Company) is in the Ordos Basin, exploration with a total area of about 37 square kilometers, and whose exploration area is highly fragmented. The situation of the pipeline rupture emerge in endlessly as the result of natural conditions and human factors each year. The first sub-factory of PCOC is located in the Yishan Slope of the Ordos Basin in Yan'an, all of the region is hilly gully region, most of the oil pipeline is laying along the topography, which is difficult for labor patrol, UAV patrol is still in stage of testing. The STX-100 four rotor industrial-grade UAV has good performance, suitable for complex area of oil pipeline patrol work, can effectively relieve the staff.
\end{abstract}

\section{Introduction}

Changqing oil field is China's largest oil and gas fields. Main exploration area in Shaanxi province, Gansu province, Ningxia hui autonomous region, Inner Mongolia, Shanxi and other five provinces of 15 cities and 61 counties (banners), the main body is in the ordos basin, which with a total area of about 37 square kilometers, and highly fragmented[1,2,3].

Each year as a result of natural conditions and human factors, leading to the situation of the pipeline rupture emerge in endlessly[4,5]. After a large number of oil spill, the plants will be dying and the land will not be plowing because of the oil infiltration in the topsoil, and polluted river or ocean killing oxygen to aquatic animals, and to polluting the air because of evaporation by sunlight exposure. People and animals inhalation or skin contact with toxic substances in huge quantities of crude oil (including benzene, toluene and xylene, etc.) [6], can cause acute and chronic poisoning, and even deadly. So oilfield company every year need to spend a lot of manpower and material resources for oil pipeline patrol work.

The first sub-factory of PCOC is located in the Yishan Slope of the Ordos Basin in Yan'an, all of the region is hilly gully region[7,8,9], most of the oil pipeline is laying along the topography, which is difficult for labor patrol. So you would like to explore drones in the pipeline patrolling, alleviate patrol staff workload. This experiment adopts the STX-100 four rotor industrial-grade UAV, the machine has features such as simple operation and good performance, through a series of oil pipeline patrol test, it can get a clear image of pipeline, and can satisfy the complex terrain and complex weather conditions of oil pipeline patrol work.

\section{The STX-100 Four Rotor Industrial-Grade UAV}

The STX-100 four rotor industrial-grade UAV has a main fuselage with the size of $1060 * 1060 \mathrm{~mm}$, and with the weight of $4 \mathrm{~kg}$ (carry a battery with $20000 \mathrm{mAh}$ ), the fuselage carrying a GOPro high definition SONY digital camera, this UAV battery life is about 40 60 minutes, wind loading for level 6 , resistance to rain to moderate rain grade, the biggest work scope could reach $12 \mathrm{~km}$, cruise way for 
autonomous cruise, remote control[10,11]. Main configuration and parameters are shown in Table 1, Table 2.

Table 1 Main configuration of the STX-100 four rotor industrial-grade UAV

\begin{tabular}{|l|l|l|}
\hline NO. & Equipment and personnel & Contains \\
\hline 1 & STX-100 four rotor industrial-grade UAV & One piece \\
\hline 2 & Portable ground control station & One set \\
\hline 3 & Staff & One operater and One support staff \\
\hline
\end{tabular}

Table 2 Main parameters of the STX-100 four rotor industrial-grade UAV

\begin{tabular}{|l|l|l|l|l|l|}
\hline Name & Battery life & Wind loading & Radius control & carrying & cruise way \\
\hline indicators & $\begin{array}{l}40 \sim 60 \\
\text { minutes }\end{array}$ & level 6 & $10 \mathrm{~km}$ & hd digital camera & $\begin{array}{l}\text { autonomous, } \\
\text { remote control }\end{array}$ \\
\hline
\end{tabular}

\section{Patrol Experimental Study}

According to the requirements of PCOC about UAV patrol, this experiment mainly aimed at the flight test and record for related data with visual range and beyond visual range at day also and thermal imaging at night; using a combination of visual range and beyond visual range flight, through the cruise way by autonomous and remote control, test the applicability of the UAV and handling, and record patrol data through the load equipment.

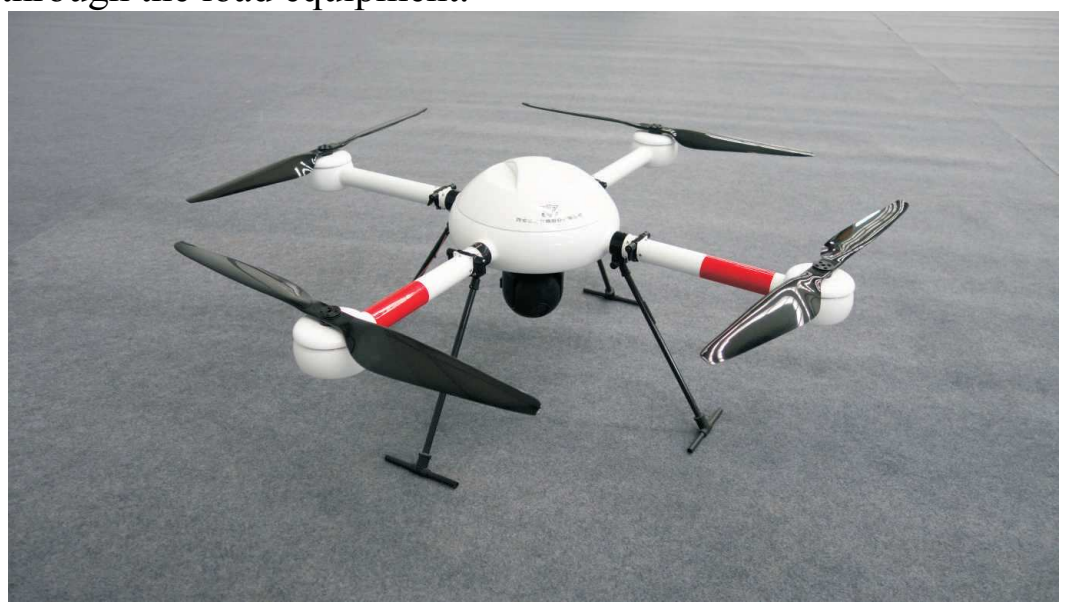

Figure 1. Finite The STX-100 four rotor industrial-grade UAV

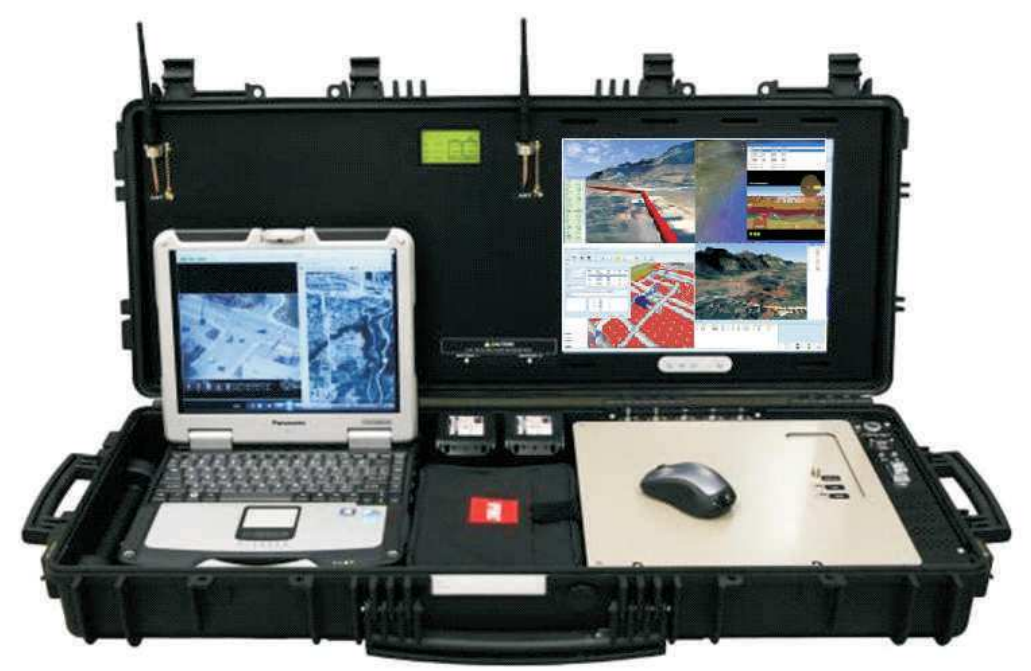

Figure 2. Finite The STGCS-100M ground station 
The complex geographical environment of the first sub-factory of PCOC, requst the performance indicators and the equipment that carrying for UAV could meeting the requirements. Put forward very high requirements on reliability, maintainability, affordable and environmental adaptability about UAV. Through on-the-spot inspections flight testing of UAV comprehensive operation ability is the most direct means.

In the process of the actual test, different location shooting back high-definition video and photo information to be able to see the actual pipeline, because of the GOPro high definition SONY digital camera, particular case is shown in Fig .3, Fig .4.

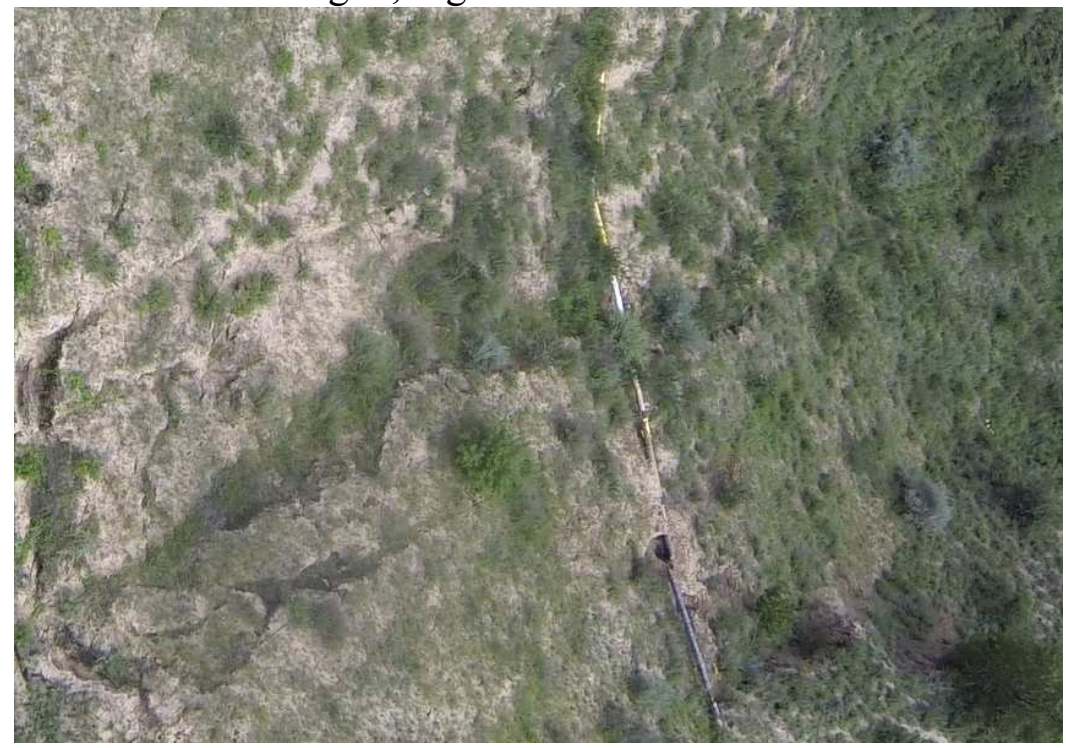

Figure 3. Finite Pipeline image along the mountain

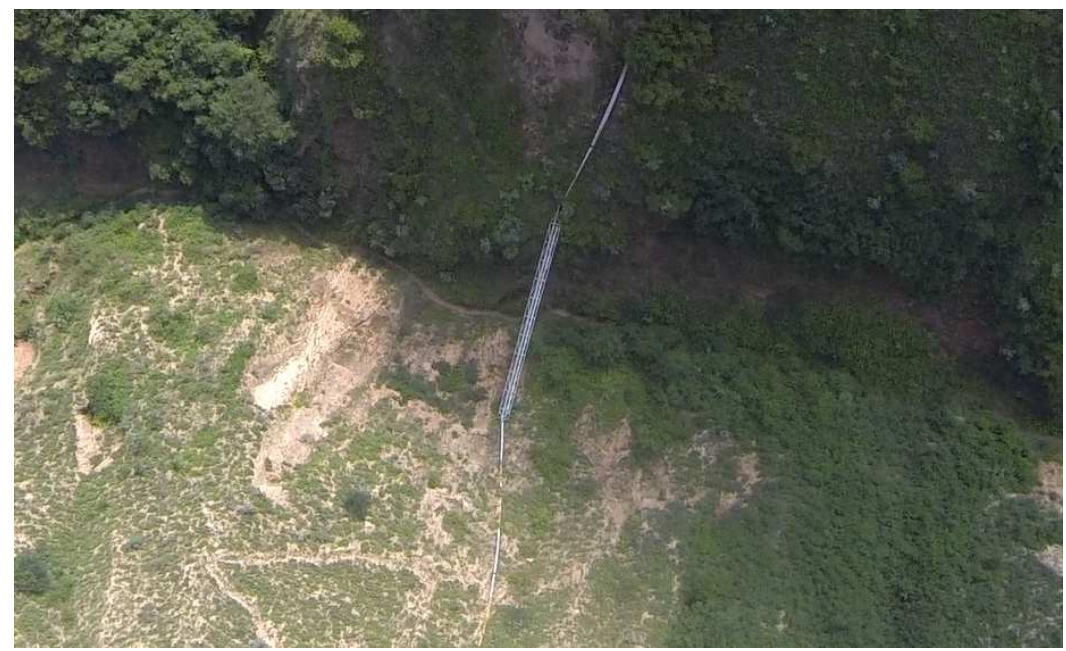

Figure 4. Finite Bridge pipeline images in valley 
Table 3 The situation of pipeline patrol

\begin{tabular}{|c|c|c|c|c|}
\hline NO. & Date & $\begin{array}{l}\text { Patrol } \\
\text { target }\end{array}$ & Patrol process & Patrol reslt \\
\hline 1 & 2016.08 .02 & $\begin{array}{l}\text { Pipeline } \\
\text { bridge }\end{array}$ & $\begin{array}{l}\text { When after liftoff that about } 1.5 \mathrm{~km} \text { to the } \\
\text { pipeline bridge, the UAV shaking because } \\
\text { of the gust, in order to guarantee safe, } \\
\text { UAV landing. }\end{array}$ & $\begin{array}{l}\text { Crosswind was so } \\
\text { strong, as the flight is } \\
\text { not stable, the patrol } \\
\text { was terminated. }\end{array}$ \\
\hline 2 & 2016.08 .03 & $\begin{array}{l}\text { Oil well, } \\
\text { Pipeline } \\
\text { bridge }\end{array}$ & $\begin{array}{l}\text { Liftoff by somewhere that about } 0.4 \mathrm{~km} \text { to } \\
\text { the pipeline bridge, UAV reach above the } \\
\text { pipeline bridge by the height of } 20 \text { meters, } \\
\text { then continue on pipeline patrolling about } \\
1.5 \mathrm{~km} \text {, and return at the last. }\end{array}$ & $\begin{array}{l}\text { Pipeline bridges and } \\
\text { lines are clearly } \\
\text { visible, } \\
\text { everything is ok. and }\end{array}$ \\
\hline 3 & 2016.08.04 & Oil well & $\begin{array}{l}\text { Liftoff in north apricot area, flying to the } \\
\text { two wells by distance of } 1.5 \mathrm{~km} \text {. }\end{array}$ & $\begin{array}{l}\text { UAV flights stability } \\
\text { quickly and real-time } \\
\text { image visible. }\end{array}$ \\
\hline 4 & 2016.08 .05 & $\begin{array}{l}\text { Pipeline } \\
\text { bridge }\end{array}$ & $\begin{array}{l}\text { Liftoff by somewhere that about } 1.8 \mathrm{~km} \text { to } \\
\text { the pipeline bridge, UAV reach above the } \\
\text { pipeline bridge by the height of } 40 \text { meters. }\end{array}$ & $\begin{array}{l}\text { Image is clearly } \\
\text { visible, pipeline } \\
\text { bridges and lines are } \\
\text { all right. }\end{array}$ \\
\hline
\end{tabular}

\section{Conclusion}

This experiment adopts the STX-100 four rotor industrial-grade UAV, whose biggest battery life is 60 minutes when cruising, and whose control station contains remote-control unit and ground control station, the operation is simple. The clarity of the image is very well, is able to see the actual pipeline, also can meet the demand of oil pipeline patrol in complex area by cruise battery life, flighting distance and automatic flight.

\section{References}

[1] Kington T. Italian UAVs patrol Iraq[J]. C4ISR: The Journal of Network-Centric Warfare, 2005.

[2] Jin G, Tang Y, Xu J. Comparison and Analysis of the Technology of UAV Patrol Line and Route Positioning[J]. Informatization Research, 2015.

[3] Wei W L, Ding J, Huang J F. Brief Analysis on the Airline Planning of Fixed Wing UAV Power Line Patrol[J]. China Electric Power, 2016.

[4] Krishnamoorthy K, Park M, Darbha S, et al. Approximate Dynamic Programming Applied to UAV Perimeter Patrol[J]. Lecture Notes in Control \& Information Sciences, 2013, 444:119-146.

[5] Oyekan J, Hu H. Towards Autonomous Patrol Behaviours for UAVs[J]. Proceedings of Uk Epsrc Workshop on Human Adaptive Mechatronics Staffordshire, 2009.

[6] Krishnamoorthy K, Park M, Darbha S, et al. Approximate Dynamic Programming Applied to UAV Perimeter Patrol[M] Recent Advances in Research on Unmanned Aerial Vehicles. 2013:119-146.

[7] Krishnamoorthy K, Pachter M, Darbha S, et al. Approximate dynamic programming with state aggregation applied to UAV perimeter patrol[J]. International Journal of Robust \& Nonlinear Control, 2013, 21(12):1396-1409.

[8] Jones D. Power line inspection - a UAV concept[J]. Iee Forum on Autonomous Systems, 2005:8 pp.

[9] Waite J W, Gudmundsson T, Gargov D. UAV power line position and load parameter estimation: US, US 20120016538 A1[P]. 2015. 
[10] Jiang W, Wenkai F, Qianru L. An Integrated Measure and Location Method Based on Airborne 2D Laser Scanning Sensor for UAV's Power Line Inspection[C] Fifth International Conference on Measuring Technology and Mechatronics Automation. IEEE, 2013:213-217.

[11]Zhang Y, Yuan X, Fang Y, et al. UAV Low Altitude Photogrammetry for Power Line Inspection[J]. 2016. 